\title{
The Research of Chinese Export and Carbon Emission
}

\author{
Huang Kanmei and Shen Minqi
}

Shanghai Zhongqiao Vocational and Technical College, Shanghai, 201209

Key words: Export, Carbon Emission, Empirical analysis, Walras-Cassel model

\begin{abstract}
Carbon emission, results in global warming, and endangers the survival and development of human society. Therefore, a series of climate change response agreement such as the "Kyoto Agreement", "Paris Agreement" are introduced. Although the United States has withdrawn from "the Paris Agreement", the development of a low-carbon economy remains an unshakable trend. Now, China's foreign trade has expanded rapidly, and the problem of carbon emission has become serious. Therefore, to explore the relationship between China's export and carbon emission, and to analyze the structure of carbon emission from export in various industries, is very helpful to develop China's future carbon reduction path and strive for greater discourse power in carbon emission. This paper will conduct an empirical analysis of the relationship between carbon emission and export trade, and use the Walras-Cassel model to compare the intensity of carbon emission across industries.
\end{abstract}

\section{Carbon Emission and the Development of China's Export Trade}

The Global Context of Carbon Emission. Carbon emission may lead to environmental problems such as rising sea levels and degradation of ecosystems etc [1-2]. The report released by the United Nations Intergovernmental Panel on Climate Change (2013) showed that the sea level is expected to rise by 0.52 to 0.98 meters by the end of the century. The annual earth report- "State of the Climate" in 2015, led by the US National Oceanic and Atmospheric Administration, showed that the year 2015 is the hottest year in the modern history which exceed the year 2014.

A series of problems brought about by climate change has long attracted the attention of the international community. From "the United Nations Framework Convention on Climate Change" to the "Paris Agreement", the greenhouse gas emission standards and emission reduction targets for countries are becoming more specific and rigorous.

As the world's largest carbon emitter, China has also made a commitment in terms of carbon emission [3-4]. When the Paris Conference on Climate Change was held in 2015, China promised until 2030, the unit GDP of carbon dioxide emission will be declined $60 \%-65 \%$ compared with 2005 [5]. However, China's energy-saving and emission-reduction is still grim: China's carbon dioxide emission in 2005 is about 5 billion tons, accounting for 18.7\% of the world, then, in 2015 it reached 10.4 billion tons, accounting for $29 \%$ [6]. Therefore, how to response to climate change has become a matter related to China's overall economic development.

The overview of China 's Export Trade. Export trade has made great contributions to China's rapid economic growth. Since the Reform and Opening up, export has been one of the "three carriages" that have boosted economic growth. According to "China Statistical Yearbook", in 1985,GDP was 901.6 billion yuan, while the total export was 80.89 billion yuan, accounting for only $8.97 \%$ of GDP; by 2016, China's GDP was 74412.7 billion yuan , while the total export trade was 13.8 trillion yuan, accounting for $18.5 \%$ of GDP. Therefore, the proportion of total export trade increased by 2.06 times.

\section{A Quantitative Study on the Relationship between Carbon Emissions and Export}

The Construction of the Model. From the economic theory, we can see that export trade will drive the production needs of domestic products, and the production process will inevitably consume energy, resulting in a certain carbon emissions, so there is the long-term stable relationship between carbon emission and export trade. In order to eliminate the heteroskedasticity and weaken the 
influence of data fluctuation, this paper will establish the econometric model by taking the logarithm as follows:

$$
\log Y_{t}=\beta+\alpha \log X_{t}+\mu_{t}
$$

Among them, $\log Y_{t}$ is the logarithm of the carbon emission in t year; $\log X_{t}$ is the logarithm of the export trade in t year; $\mu_{t}$ is a random error. If $\alpha>0$, the export and China's carbon emission show a positive correlation; if $\alpha<0$, it shows that the export can reduce China's carbon emissions.

Then, firstly, it need to pass the ADF test, as follows:

$$
\left\{\begin{array}{l}
\Delta \log Y_{\mathrm{t}}=\xi \log Y_{t-1}+\sum_{j=1}^{\rho} \rho_{j} \Delta \log Y_{t-j}+\mu_{t} \\
\Delta \log Y_{\mathrm{t}}=z+\xi \log Y_{t-1}+\sum_{j=1}^{\rho} \rho_{j} \Delta \log Y_{t-j}+\mu_{t} \\
\Delta \log Y_{\mathrm{t}}=z+\lambda t+\xi \log Y_{t-1}+\sum_{j=1}^{\rho} \rho_{j} \Delta \log Y_{t-j}+\mu_{t}
\end{array}\right.
$$

Secondly, in order to ensure the stability, the article will use the maximum likelihood principle for cointegration test.

Furthermore, the Error Correction Model (ECM) was established to analyze the short-term dynamic relationship between variables. The selected model is as follows:

$$
\Delta \log Y_{\mathrm{t}}=\alpha \Delta \log X_{t}+\beta \log Y_{t-1}+\eta \Delta \log X_{t-1}+\omega E C M_{t-1}+\mu_{t}
$$

Among them $E C M_{t-1}$ is the long-term equilibrium deviation and $\omega$ is the short-term adjustment factor. According to Equation 2, it can be found that ECM combines the level and differential values of the variables. In the short term, $\Delta \log Y_{t}$ is determined by the more stable long-term trend- $E C M_{t-1}$ and short-term fluctuations- $\Delta \log X_{t} 、 \Delta \log Y_{t-1} 、 \Delta \log X_{t-1}$.

Finally, the Granger test is used to determine the long-term relationship between carbon emissions and exports. The following is the Granger causality test model:

$$
\left\{\begin{array}{l}
\log Y_{t}=\sum_{i=1}^{q} \alpha_{i} \log X_{t-i}+\sum_{j=1}^{q} \beta_{j} \log Y_{t-j}+\mu_{1 t} \\
\log X_{t}=\sum_{i=1}^{n} \rho_{i} \log X_{t-i}+\sum_{j=1}^{n} \delta_{j} \log Y_{t-j}+\mu_{2 t}
\end{array}\right.
$$

The original hypothesis is:

$$
\left\{\begin{array}{l}
H_{01}: \alpha_{1}=\alpha_{2}=\alpha_{3}=\ldots=\alpha_{\mathrm{q}}=0 \\
H_{02}: \delta_{1}=\delta_{2}=\delta_{3}=\ldots=\delta_{\mathrm{n}}=0
\end{array}\right.
$$

Where $\mu_{1 t}$ and $\mu_{2 t}$ are irrelevant.

An Empirical Test on the Relationship between Carbon Emissions and Export. Data Selection. Due to the complexity and controversy of the data, this paper selected the carbon emissions data from 1985 to 2011, because the carbon data of this period, is less controversial in the international community, and the statistical results from all parties are less different. And then, from the "China Statistical Yearbook", the annual nominal export trade can be found. According to the base period-1985, the actual export trade can be computed. In addition, in order to prevent the emergence of heteroscedasticity, the data were logarithmic in the article.

Stationarity and Cointegration Test. Through EVIEWS, using the GENR command, it can be found that the p value of ADF statistics about $\log Y, \log X$ is $0.9030,0.2829$, which is greater than 0.05 , so they are not stable. After that, selecting the GENR command for the variable again, $\triangle \log Y$ can be got from $\log Y, \triangle \log X$ can be got from $\log X$, and the new first order differential sequence is shown in Figure 1. Then, according to the unit root test, from Table 1,the p value of ADF statistics about $\Delta \log Y$ and $\Delta \log X$ is $0.0370,0.0008$, which is less than 0.05 , so the variable is stable. 
Table 1 Unit Root Test Results

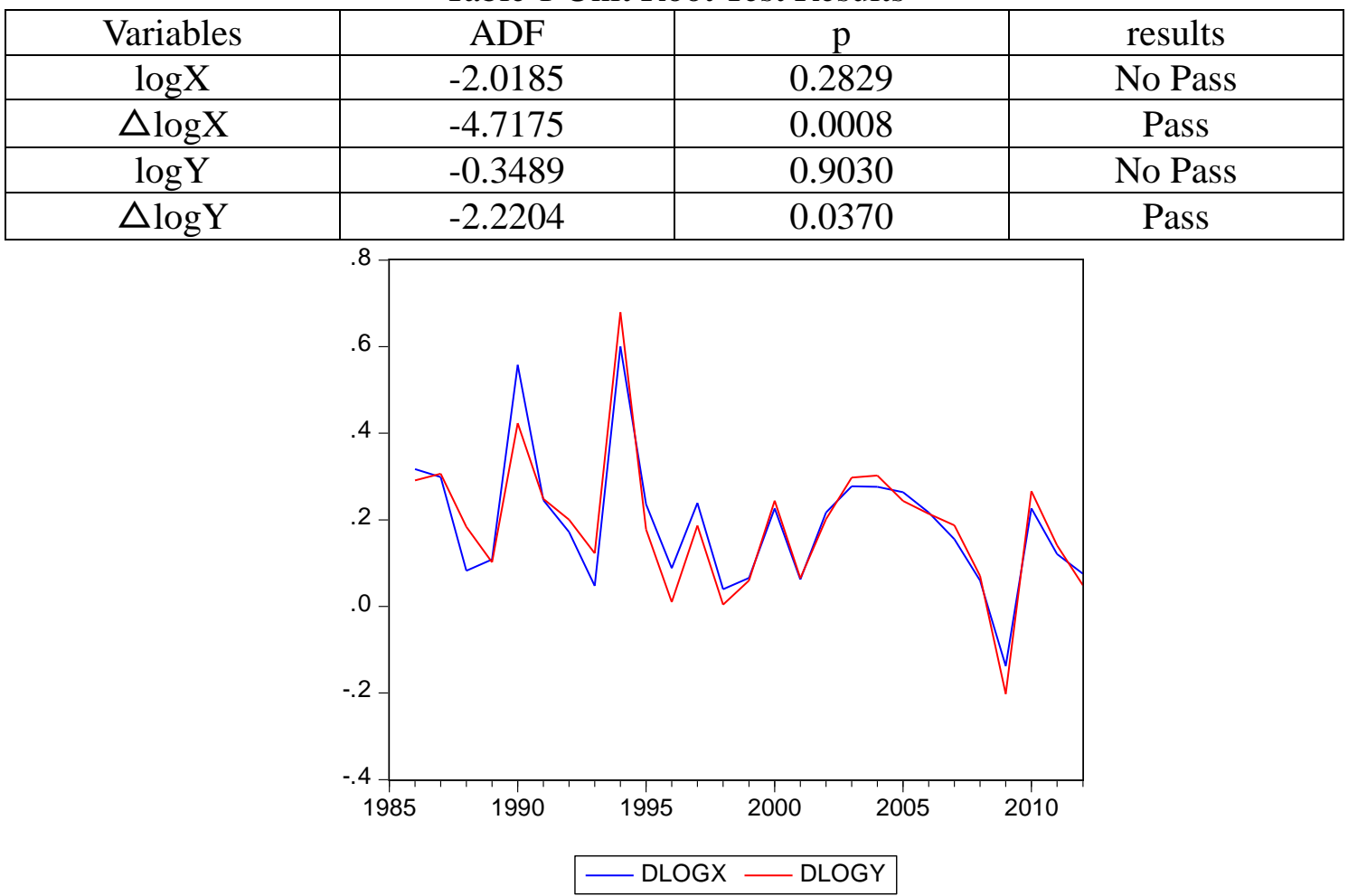

Figure 1 First order differential logarithmic sequence diagram of carbon emissions (Y) and export trade $(\mathrm{X})$

Cointegration Test. According to the ADF test, $\Delta \log \mathrm{Y}$ and $\Delta \log \mathrm{X}$ are stationary, so the cointegration can be done. The results of the following Tables 2 and 3 are obtained by the maximum likelihood test by EVIEWS6.0.

Table 2 the Results about the cointegration of the characteristic root trace test

\begin{tabular}{|c|c|c|c|c|}
\hline $\begin{array}{c}\text { Original hypothe } \\
\text { sis }\end{array}$ & eigenvalue & $\begin{array}{c}\text { Trace } \\
\text { Statistics }\end{array}$ & $\begin{array}{c}\text { The critical value of } \\
\text { significantly 5\% }\end{array}$ & adjoint probability: $p$ \\
\hline $\begin{array}{c}\text { no cointegration } \\
\text { vector }\end{array}$ & 0.4374 & 18.6885 & 15.5047 & 0.0152 \\
\hline $\begin{array}{c}\text { cointegration } \\
\text { vector }\end{array}$ & 0.1335 & 3.7321 & 3.8448 & 0.0522 \\
\hline
\end{tabular}

Table 3 the Results about the cointegration of the characteristic root trace test

\begin{tabular}{|c|c|c|c|c|}
\hline $\begin{array}{c}\text { Original hypothe } \\
\text { sis }\end{array}$ & eigenvalue & $\begin{array}{c}\text { Trace } \\
\text { Statistics }\end{array}$ & $\begin{array}{c}\text { The critical value of } \\
\text { significantly 5\% }\end{array}$ & adjoint probability: $p$ \\
\hline $\begin{array}{c}\text { no cointegration } \\
\text { vector }\end{array}$ & 0.4374 & 14.9563 & 14.2566 & 0.0152 \\
\hline $\begin{array}{c}\text { cointegration } \\
\text { vector }\end{array}$ & 0.1335 & 3.7321 & 3.8448 & 0.0522 \\
\hline
\end{tabular}

From the above two tables, according to the test level of 0.05 , the trace statistics test: $18.69>$ $15.50,3.73<3.84$; the eigenvalue test: $14.96>14.26$, $3.73<3.84$.

Therefore, according to the above analysis, there are cointegration relationship in $\Delta \log Y$ and $\Delta \log X$ sequence. And the long relationship of two variates is: $\Delta \log Y=0.41 \Delta \log X$, which shows that carbon emission and export has a positive correlation, and in the long run, export increases by $1 \%$, while carbon emission increases by $0.41 \%$.

Error Correction Model (EMC) and Granger Causality Test. Error Correction Model (EMC). The long-term relationship between carbon emissions and export trade has been obtained by cointegration analysis. And the short-term relationship between them will be studied by error 
correction model. Use EVIEWS to get the error correction model as follows:

$$
\Delta \log Y_{t}=0.020+0.429 \Delta \log X_{t}+0.293 \Delta \log Y_{t-1}+0.055 \Delta \log X_{t-1}-0.1532 E C M_{t-1}
$$

$$
R^{2}=0.516 \quad \bar{R}^{2}=0.477 \quad D W=1.71 \quad F=5.12
$$

Among them, there is t statistic in the brackets. According to the judgment by the standard of DW test, when it is greater than 0 and less than zero boundary value- $\mathrm{d} L$, so there is the positive sequence correlation between variables. After refering to the table, $D W=1.71$ can be found, which belongs to the range. Therefore, the model passes the DW test. In addition, by EVIEWS: $F=$ 5.12, which is less than the $\mathrm{F}$ value found from the table, indicating that there is no significant difference between the two variables. Therefore, the model passes the F test. From the $t$ test, in the 95\% confidence interval, the original hypothesis can be accepted, so there is no significant difference between the two variables. From the regression equation, it can be found that $\triangle \log X$, $E C M_{\mathrm{t}-1}$ also passes the $\mathrm{t}$ test. And the sign of $\triangle \log X$ in the model and the $\triangle \log X$ in the cointegration equation are positive, however the error correction coefficient is less than 0 , which conforms to the reverse correction mechanism.

It is clear that China's carbon dioxide emission and export trade changing in the same direction. In the short term, the export trade increases by $1 \%$, while carbon emission increases by $0.43 \%$. The significance of the short-term adjustment coefficient indicates that the actual carbon emission per year is $15.32 \%$ offset from the long-term equilibrium, which has been corrected.

All in all, the export trade and China's carbon emission is closely related.

Granger Causality Test. From the cointegration test and error correction model, $\log Y$ and $\log X$ can be seen in the long term and short-term relationship, but the causal relationship between them is not clear. To solve this problem, Granger causality test is used in the article to determine, and the test results can be seen in Table 4 . The $P$-value in the table is the concomitant probability of the $F$-test, which is also the criterion for the Granger causality test, that is, when $P<0.05$, the original hypothesis is rejected.

From the test results in Table 4, it can be seen that there is a two-way causal relationship between China's carbon emissions and export trade at 95\% confidence level. It can be found in China's export trade structure, the extensive industry of high energy consumption, high pollution, accounted for a considerable proportion. The rapid development of export trade is at the cost of large quantities of carbon emission. Export trade and domestic consumer demand, investment together, has become a major reason for China's substantial increase in carbon emission.

Table 4 Granger Causality Test Results of Export Trade and China's Carbon Emission

\begin{tabular}{|c|c|c|c|}
\hline Lag phase & Original hypothesis & F statistics & P \\
\hline \multirow{2}{*}{1} & Y isn't the Granger test of X & 23.1279 & $7 . E-05$ \\
\cline { 2 - 4 } & X isn't the Granger test of Y & 30.0867 & 1. E-05 \\
\hline \multirow{2}{*}{2} & Y isn't the Granger test of X & 14.1294 & 0.0001 \\
\cline { 2 - 4 } & X isn't the Granger test of Y & 17.1487 & 4. E-05 \\
\hline \multirow{2}{*}{3} & Y isn't the Granger test of X & 7.93464 & 0.0011 \\
\cline { 2 - 4 } & X isn't the Granger test of Y & 8.79812 & 0.0007 \\
\hline \multirow{2}{*}{4} & Y isn't the Granger test of X & 8.95671 & 0.0008 \\
\cline { 2 - 4 } & X isn't the Granger test of Y & 9.84312 & 0.0009 \\
\hline \multirow{2}{*}{5} & Y isn't the Granger test of X & 9.07246 & 0.0002 \\
\cline { 2 - 4 } & X isn't the Granger test of Y & 9.89314 & 0.0005 \\
\hline \multirow{2}{*}{6} & Y isn't the Granger test of X & 5.05380 & 0.0145 \\
\cline { 2 - 4 } & X isn't the Granger test of Y & 4.63741 & 0.0300 \\
\hline
\end{tabular}

In conclusion, according to the above empirical test, it can be concluded that there is a positive correlation between China's carbon emission and China's export trade, and export trade does bring about China's carbon emissions. In the long run, for every $1 \%$ increase in exports, carbon emission will increase by $0.41 \%$. In the short term, the carbon emission will increase by $0.43 \%$ for every $1 \%$ 
increase in export.

\section{The Industry Analysis of Carbon Emission from the Export Trade}

The Construction of the Model. According to the previous analysis, the energy consumed in the export of goods produced is one of the main causes of carbon emission from export trade. The product of the carbon emissions coefficient from the energy and the energy consumption of the export trade is the amount of carbon emission from the export trade. But China has no specific data on the energy consumption of export products. Therefore, the input-output method, and the Walras-Cassel model is used in this paper, to calculate the energy consumption of export trade goods, and ultimately obtain the proportion of export trade carbon emission and the total carbon emission. According to the input-output table, the equations are as following:

$$
X=(I-A)^{-1}(Y+N X)
$$

Where $A=\left[\begin{array}{cccc}a_{11} & a_{12} & \ldots & a_{1 n} \\ a_{21} & a_{22} & \ldots & a_{2 n} \\ \ldots & \ldots & \ldots & \ldots \\ a_{n 1} & a_{n 2} & \ldots & a_{n n}\end{array}\right], a_{i j}=x_{i j} / X_{j}(i, j=1,2, \ldots n)$.

$X_{j}$ is the $j$ sector of the total output; $x_{i j}$ refers to the production of the sector $\mathrm{j}$ need to consume the number of products of $i$ sector . The value of the direct consumptive coefficient is generally between 0 and 1 . If the value is greater, it is more dependence of the $j$ sector on the $i$ sector, and vice versa. In the study of input-output, the matrix is used to represent the direct consumptive coefficient, which is called the matrix of direct consumptive coefficient, and represent by A.

$X$ is the total output; $Y$ is the final product column vector; $N X$ is the net export; $N X=E-M$, where $E$ and $M$ indicates the amount of export and the import. In the official input-output data, the total output of the $j$-th sector consume the sum of the products and raw materials imported from both the domestic and foreign sectors.

In the following, the import factor q is introduced to represent China's true total output and total investment better. Let $Q$ be the matrix of the input coefficient , then there are:

Substituting Formula 5 into Formula 4:

$$
\left\{\begin{array}{l}
M=Q(A X+Y) \\
q_{j}=\frac{m_{j}}{\sum_{i=1}^{n} a_{i j} x_{j}+y_{j}}
\end{array}\right.
$$

$$
X=[I-(I-Q) A]^{-1}[(I-Q) Y+E]
$$

Let $B=[I-(I-Q) A]^{-1}$, and $B$ is the matrix of the complete consumptive coefficient, then (6) can be changed to:

$$
X=B(I-Q) Y+B E=X_{i}+X_{e}
$$

It can be seen from the formula (7) that the total output of domestic demand $X_{\mathrm{i}}$, together with the total output of export demand $X_{\mathrm{e}}$, constitute the total output of national demand.

According to the Walras-Cassel model:

$$
R=W X
$$

The matrix expansion is:

$$
\left[\begin{array}{c}
r_{1} \\
r_{2} \\
\vdots \\
r_{m}
\end{array}\right]=\left[\begin{array}{cccc}
w_{11} & w_{12} & \cdots & w_{1 n} \\
w_{21} & w_{22} & \ldots & w_{2 n} \\
\ldots & \cdots & \cdots & \cdots \\
w_{m 1} & w_{m 2} & \cdots & w_{m n}
\end{array}\right]\left[\begin{array}{c}
x_{1} \\
x_{2} \\
\vdots \\
x_{n}
\end{array}\right]
$$


Among them, $W$ : matrix of the energy consumption coefficient; $W_{\mathrm{ij}}$ : production of unit product from $j$ industry will consume $i$ energy, $R$ refers to the total resources and services.

China's domestic and export trade consumption is:

$$
R_{e}=W X_{e}
$$

The calculation of the industry and total carbon emission based on China's total output is as follows:

$$
\begin{gathered}
D_{e}=C R_{e}=C W X_{e} \\
D=C R=C W X
\end{gathered}
$$

$D$ is the total carbon emission of the industry; $D_{\mathrm{e}}$ is the export carbon emission of the industry; and $C$ is the matrix of carbon emission from the energy consumption.

Data Selection. As now Chinese statistical angencies is in the preparation of the input-output table, only in the year of mantissa 2 and 7. And in the year of mantissa 0 and 5, they will in the preparation of input-output extension table. In this paper, for the rationality and objectivity of the data, it is calculated only by total carbon emission and export trade carbon emission in China in 2002, 2005, 2007 and 2010,according to the formulas (10) and (11).

The carbon emission coefficient comes from Zhou Dadi "China Sustainable Energy Scenario" (as shown in Table 5).It is energy consumption and total output of China's various industries in different years (From this, the matrix of energy consumption coefficient is available), China's amount of import and the total output of the industry in different years(the matrix of import coefficient can be obtained), the matrix of direct consumption coefficient in different years, the export of each industry and the final output being derived from the "China Statistical Yearbook".

Table 5 the carbon emission coefficient of energy

\begin{tabular}{|c|l|l|l|}
\hline Energy & Coal & Oil & Gas \\
\hline Carbon emission coefficient & 0.748 & 0.583 & 0.444 \\
\hline
\end{tabular}

Data Sources: Zhou Dadi China Sustainable Energy Scenario[M] Beijing: China Environmental Science Press,2005: 31-32

Result Analysis. According to the formula (11), it is not difficult to draw the conclusion of the carbon emission from export trade of various sectors in 2002, 2005, and 2010,and the industry's own carbon emission, and then calculate the ratio between export carbon emission of various industries and total carbon emission in four years, which is shown in Figure 2:

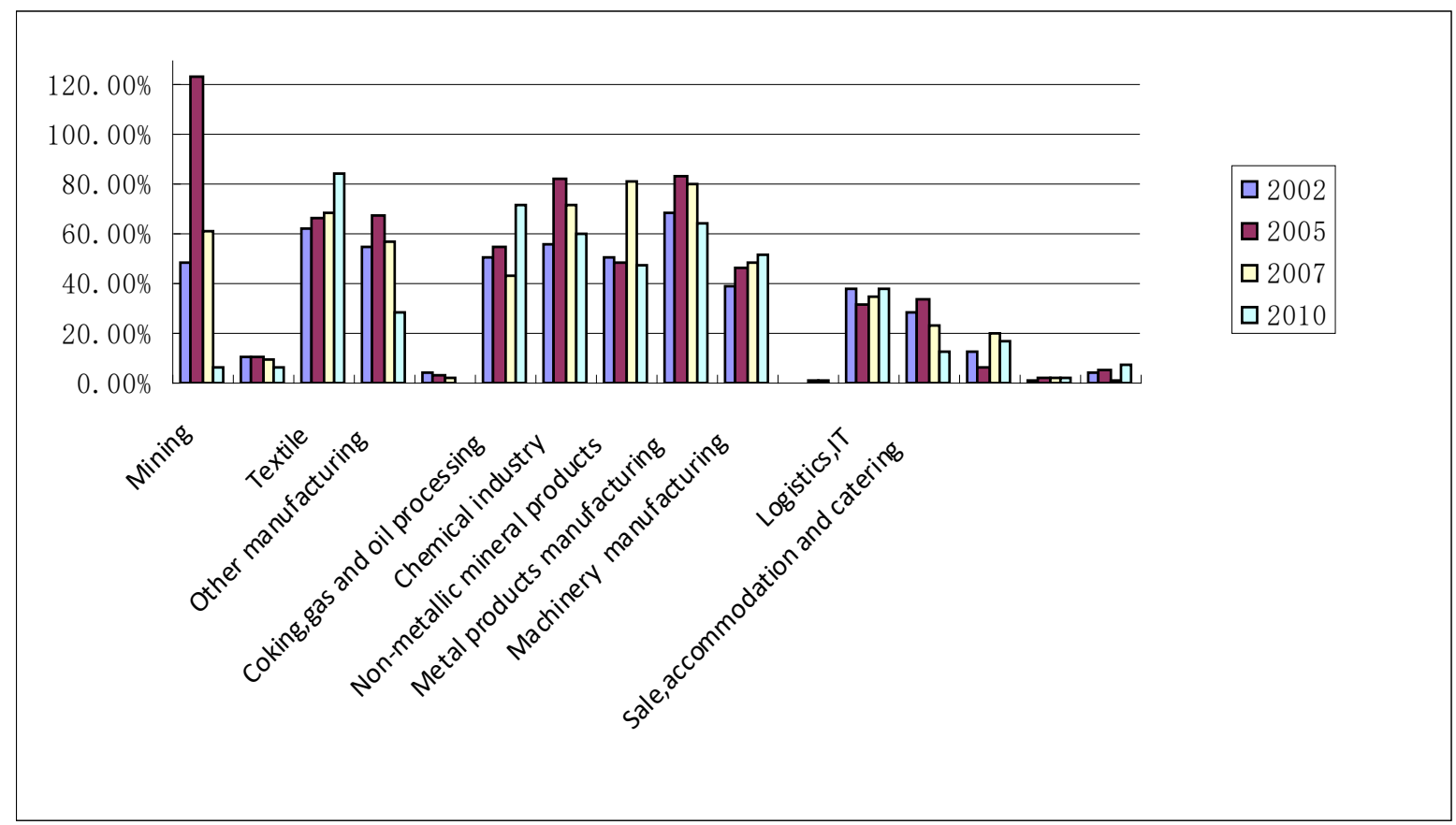

Figure 2 The contribution of carbon emission from industries in four years

In the past four years, the industries which discharged of carbon accountting for the seven largest proportion of China's total carbon emission was: metal products manufacturing, mining, chemical 
industry, textile, machinery manufacturing, coking gas and oil processing and non - metallic mineral products.

In addition, the carbon emission of logistics and IT accounted for $20 \%$ to $40 \%$ of China's total carbon emissions, and it is below 20\% the export carbon emission of the remaining sectors accounting for the proportion of China's total carbon emission. It can be seen that the export of the industry of high pollution and high energy consumption has a significant impact on China's carbon emissions.

\section{China's Strategy to Export Carbon Emission}

Optimize the Export Structure. It is not sustainable to promote export by industries of high energy consumption, high carbon emission. According to the previous analysis, these industries accounts for a large proportion of total carbon emission. Therefore, to reduce carbon emissions, it is needed to change the export pattern.

Export mainly relied on industrial products, especially primary industrial products should be declined, and be committed to the development of service trade. The service trade on the one hand, is low energy consumptting, high added value and sustainable, on the other hand, it also promotes the international transfer of knowledge and technology, so it has more advantages and competitiveness than traditional industries, which is great significant to optimize export structure and control carbon emission. Therefore, developing service trade is the inevitable choice to optimize the export structure.

Promote the Energy Price Marketize. If a country's energy saving and emission reduction only relies on mandatory administrative means, it will make energy-saving emission reduction in the form, and pay huge social cost. On the contrary, if the price of energy is marketize, the invisible hand can optimize the allocation of resources. As Chinese government offers government guide price of energy for a long time, the scarcity of energy can not be reflected in the price, and the main performance is the energy price is lower than the market price, which will lead to the whole society uncontrolled using even wasting energy. In order to prompt the energy price leverage to play a role in energy conservation and emission reduction, it is necessary to break the existing energy market which is administrative intervened by government and monopolized by state-owned enterprise, and deepen the system reform, accelerate the energy price marketize.

Strengthen the International Cooperation in Carbon Reduction. Low-carbon emission is not a matter of one country, therefore, international low-carbon emission cooperation need to be strengthened, so that countries can learn advanced experience from each other, and share achievement, jointly promote this carrer of all mankind.

In the framework of the "Paris Agreement", developed countries set up emission reduction projects. On the one hand it can reduce the cost of self-reduction, on the other hand, China can also get advanced technology and capital from developed countries to promote its own low-carbon emission.

\section{References}

[1]Glen P Peters, Edgar G Hertwich. Pollution embodied in trade: the Norwegiancase [J]. Global Environmental Change, 2006, 16(4): 379-387

[2] Nadim Ahmad, Andrew W Wyckoff. Carbon dioxide emissions embodied international trade of goods [EB/OL].2009-04-15.

[3]Yu Yang, Chen Fei-fan. Research on carbon emissions embodied in trade between China and South Korea: Atmospheric Pollution Research [J]. 2016, 07(7)

[4]Shuai Shao, Jianghua Liu, Yong Geng, Zhuang Miao, Yingchun Yang. Uncovering driving factors of carbon emissions from China's mining sector: Applied Energy[J].2016,01

[5]Jinhe Jiang. China’s urban residential carbon emission and energy efficiency policy: enrgy: 2016, 
$05(6)$

[6]Zhou Dadi China Sustainable Energy Scenario [M] Beijing: China Environmental Science Press, 2005: 31-32 